\title{
Clinical outcomes of primary vitrectomy in pseudophakic retinal detachment
}

\author{
Katarzyna Nowomiejska', Agnieszka Kalinowska', Dominika Nowakowska', \\ Agnieszka Brzozowska², Anselm G. Jünemann, Robert Rejdak ${ }^{1,4}$ \\ 'Department of General Ophthalmology, Medical University, Lublin, Poland \\ ${ }^{2}$ Department of Mathematics and Medical Biostatistics, Medical University, Lublin, Poland \\ ${ }^{3}$ University Eye Hospital, Department of Ophthalmology, Rostock, Germany \\ ${ }^{4}$ Department of Experimental Pharmacology, Medical Research Centre, Polish Academy of Sciences, Warsaw, Poland
}

\begin{abstract}
PURPOSE. To evaluate the efficacy of primary pars plana vitrectomy (PPV) for rhematogenous retinal detachment (RD) in pseudophakic eyes.

MATERIALS AND METHODS. The medical records of 63 patients who had undergone PPV after phacoemulsification were reviewed retrospectively. The mean follow-up period was 10 months. Statistical analysis evaluated functional and anatomical results as well as general (diabetes, hypertension) and ocular (myopia, glaucoma, floppy iris syndrome, intraoperative complications during cataract surgery, YAG capsulotomy) conditions.

RESULTS. The median period from cataract surgery to RD onset was 15 months. Retinal attachment was achieved in $92 \%$ of eyes. The final visual acuities were improved significantly from $1.7 \log$ MAR to $0.7 \log$ MAR. Silicon oil was used as a tamponade in 38 eyes and SF6 gas in 25 eyes. Better functional results were achieved with SF6 gas tamponade. No intraoperative complications were reported. Most of the patients were males (71\%). Statistical analysis revealed that general and ocular conditions did not influence functional results.

CONCLUSIONS. Primary PPV, especially with gas as a tamponade, is an effective procedure in the surgical treatment of pseudophakic RD. The advantages include good anatomical and functional outcomes and low complication rate. Neither clinical nor surgical factors have been identified as responsible for the visual outcomes.
\end{abstract}

KEY WORDS: retinal detachment, primary vitrectomy, pseudophakia

Ophthalmol J 2016; Vol. 1, No. 1, 24-28

\section{INTRODUCTION}

Pseudophakic retinal detachment $(\mathrm{RD})$ is one of the most serious complications of the cataract surgery, potentially blinding. The estimated incidence of $\mathrm{RD}$ is about $0.2-1.7 \%$ in the first year after cataract surgery, even with modern, small-incision surgical techniques $[1,2]$. Thus, $\mathrm{RD}$ is much more common postsurgical complication than endophthalmitis $(0.05 \%)$ and suprachoroidal haemorrhage $(0.2 \%)$. It is estimated that in normal eyes the annual incidence of $\mathrm{RD}$ is between 6.3 and 17.9 per 100,000 of population per year (about $0.01 \%$ ) [3].
Thus, the risk of $\mathrm{RD}$ is four-times higher in eyes after cataract surgery than in phakic eyes [4]. Since phacoemulsification is the most common and effective intraocular surgery, pseudophakic RD compromises an increasing proportion of RDs. It is supposed that about $20-40 \%$ of all RD surgeries have been performed in eyes with cataract surgery in the history.

It has been reported that RDs in pseudophakic eyes are usually more extensive, and macular involvement and proliferative vitreoretinopathy (PVR) are also much more common than RDs in 
phakic eyes [5]. The tears responsible for pseudophakic $\mathrm{RD}$ are often small and anteriorly placed at the insertion of the vitreous band [6]. Many studies have shown that pars plana vitrectomy (PPV) is superior to scleral buckling surgery in eyes with pseudophakia [7], giving better anatomical and functional outcomes [8]. Modern PPV techniques offer advantages over scleral buckling surgery in eyes with pseudophakic RD [9] by less operating time and higher reattachment rate. However, there are many studies proving that there are comparable results of these two techniques [10].

The goal of this study was to analyse the functional and anatomical outcomes of primary PPV in eyes with $\mathrm{RD}$ following routine cataract surgery.

\section{METHODS}

This retrospective study included consecutive cases undergoing primary PPV for pseudophakic RD between January 2013 and December 2015 in the Department of General Ophthalmology in Lublin, Poland - the tertiary ophthalmic care referral centre for south-eastern Poland. The medical records of 63 consecutive patients were reviewed, ensuring patients' anonymity. Informed consent was obtained from each patient before inclusion of his/her data in a database. This research followed the tenets of the Declaration of Helsinki.

Patient information regarding gender, age, detailed history, visual acuity, intraocular pressure, anterior and posterior slit-lamp examination, indirect fundoscopy, and B-ultrasonography were taken into account. Anatomical success was defined as a reattached retina at the last postoperative follow-up visit. Functional outcome was recorded as best-corrected visual acuity (BCVA) with a Snellen chart at the initial (preoperative) visit and at the final follow-up visit. BCVA was converted to the logarithm of the minimum angle of resolution (logMAR) units for statistical analysis. Eyes were excluded from the study if they had previous trauma, uveitis, macular hole, glaucoma, trans-scleral fixated intraocular lens, or anterior chamber intraocular lens. Intraoperative findings of cataract surgery were recorded. The time interval between cataract surgery and RD as well as follow-up period were recorded in months. The median duration of hospital stay was three days. The follow-up examination included: visual acuity, intraocular pressure, and retinal attachment assessed with fundus examination after dilatation. Follow-up examinations were performed on the next day, at two weeks, three months, six months, nine months, and one year.

\section{STATISTICAL ANALYSIS}

Statistical computations were performed using STATISTICA 10.0 software (StatSoft, Poland). Qualitative variables were described by percentages and quantitative variables by median \pm standard deviation (SD). Wilcoxon test was used for assessment of BCVA results. Differences between groups were assessed using the Mann-Whitney $U$ test. Correlation analysis was conducted using the Spearman test. To assess variables influencing BCVA data mining methods were used. Statistical significance was set at 0.05 for all the tests.

\section{SURGICAL TECHNIQUE}

The standard surgical technique of cataract surgery was phacoemulsification through a small incision $(2.2-2.6 \mathrm{~mm})$ with the implantation of the intraocular lens. Legacy and Infiniti (Alcon Fort Worth, Texas) equipment was used for phacoemulsification surgery. Cataract surgery was performed on four eyes in our university hospital and performed on the remaining 59 eyes in other district ophthalmology hospitals.

Three-port 23G PPV was performed under general or peribulbar anaesthesia as a standard surgical procedure in the treatment of $\mathrm{RD}$ using $\mathrm{BIOM}$ (Binocular indirect ophthalmo-microscope) and Constellation (Alcon, Fort Worth, Texas) equipment. In all eyes central and peripheral vitreous was removed, followed by removal of all vitreous traction on retinal tears. The retina was flattened with PFCL or air, simultaneous drainage through the tear was performed and cryopexy or laser barrage was done around retinal breaks. At the end of the operation a mixture of $20 \%$ air and SF6 (sulphur hexafluoride) gas or 5000 centistokes silicone oil tamponade was given. The patients were advised to maintain a face-down position for 12 hours daily for one week postoperatively.

\section{RESULTS}

The data included 45 (71\%) male and 18 (29\%) female subjects (male:female ratio 2:1) with a mean age of 69 years (range 40-91 years). The median age of male subjects was $67 \pm 11$ years, and for female subjects it was $73 \pm 10$ years. The median follow-up 
Table 1. Overall best-corrected visual acuities (BCVA) (logMAR) before and after pars plana vitrectomy

\begin{tabular}{|l|c|c|c|c|c|}
\hline BCVA (logMAR) & Mean & Standard deviation & Lower quartile & Median & Upper quartile \\
\hline Preoperatively & 1.58 & 0.75 & 1.00 & 1.70 & 2.40 \\
\hline Postoperatively & 0.92 & 0.65 & 0.40 & 0.70 & 1.40 \\
\hline Wilcoxon test $Z=5.23 ; p<0.000001$ & & & \\
\hline
\end{tabular}

Table 2. Best-corrected visual acuities (BCVA) (logMAR) in female and male subjects before and after pars plana vitrectomy

\begin{tabular}{|l|c|c|c|c|c|c|c|c|c|}
\hline BCVA (logMAR) & \multicolumn{3}{|c|}{ Females } & \multicolumn{3}{c|}{ Males } & \multicolumn{2}{c|}{ Mann-Whitney test } \\
\hline & Mean & Median & SD & Mean & Median & SD & Z & P \\
\hline Preoperatively & 1.31 & 1.20 & 0.69 & 1.69 & 2.10 & 0.76 & 1.91 & 0.06 \\
\hline Postoperatively & 1.00 & 1.00 & 0.55 & 0.89 & 0.70 & 0.69 & -0.92 & 0.36 \\
\hline
\end{tabular}

period was 10 months (range 6-27 months). The right eye was operated in $49 \%$ of patients and the left eye in the remaining $51 \%$ of patients. The median time interval between cataract surgery and onset of RD was 15 months (range 6-13,505 days). Overall, median preoperative BCVA was $1.7 \log$ MAR $( \pm 0.75)$, and median postoperative BCVA was 0.7 $\log$ MAR $( \pm 0.65)(\mathrm{p}=0.0000001)$ (Tab. 1). Preoperative BCVA in male subjects was $2.1 \log \mathrm{MAR}( \pm 0.76)$ and 1.2 logMAR $( \pm 0.69)$ in female subjects $(\mathrm{p}=0.06)$. Postoperatively BCVA was $0.7 \log$ MAR $( \pm 0.69)$ and $1.0 \log$ MAR, $( \pm 0.55)$, respectively $(\mathrm{p}=0.36)($ Tab. 2$)$.

General chronic diseases (hypertension, diabetes) were found in 28 (44\%) patients, myopia in $12(19 \%)$ patients, glaucoma in $11(17 \%)$ patients, PEX in one patient (1.5\%), and floppy iris syndrome in one $(1.5 \%)$ patient. Intraoperative complications during cataract surgery were reported in eight $(13 \%)$ patients. The history of Nd:YAG capsulotomy was reported in three cases (5\%). Statistical analysis did not show any influence of these variables on the BCVA ( $p$ > 0.05) (Tab. 2). There was also no correlation between BCVA and age of operated patients $(\mathrm{p}>0.05)$.

The position of retinal breaks was superior in 27 eyes (42\%), inferior in 24 eyes (38\%), temporal in 18 eyes (29\%), and nasal in six eyes (10\%) (more than one position possible in one eye). Total RD was observed in seven cases, choroidal detachment associated with hypotony was reported in four cases, and PVR (grade C1 or more) was observed in five cases. The primary reattachment rate was $92 \%$ (58 eyes). No intraoperative complications were registered.

Silicon oil was used as a tamponade in 38 eyes $(60 \%)$ and gas SF6 in 25 (40\%) eyes. Median pre-

\begin{tabular}{|l|c|c|}
\hline \multicolumn{3}{|l|}{ Table 3. Different variables possibly influencing } \\
visual outcomes \\
\hline Variables & $\mathbf{n}$ & $\%$ \\
\hline Myopia & 12 & 19.05 \\
\hline Pseudoexfoliation & 1 & 1.59 \\
\hline Glaucoma & 11 & 17.46 \\
\hline Floppy iris syndrome & 1 & 1.59 \\
\hline $\begin{array}{l}\text { Intraoperative complications } \\
\text { during cataract surgery }\end{array}$ & 8 & 12.70 \\
\hline $\begin{array}{l}\text { General disease (diabetes, } \\
\text { hypertension) }\end{array}$ & 28 & 44.44 \\
\hline Nd:YAG capsulotomy & 3 & 5 \\
\hline
\end{tabular}

operative BCVA was statistically much worse in eyes classified to silicone oil tamponade (2.1 $\log$ MAR $\pm 0.65)$ than in eyes classified to SF6 tamponade $(1.0 \operatorname{logMAR} \pm 0.77)(\mathrm{p}=0.003)$. Median postoperative $\mathrm{BCVA}$ was $1.0 \log \mathrm{MAR} \pm 0.59$ in the silicone oil group and $0.4 \log$ MAR \pm 0.70 in the SF6 group $(\mathrm{p}=0.02)$ (Tab. 3). Raised intraocular pressure was observed postoperatively in $20 \%$ of eyes; it was treated with topical antiglaucomatous agents.

Additional statistical analysis (data mining) showed that male subjects had better BCVA than female subjects, patients older than 70 years suffering from general disease had worse BCVA than younger subjects, and eyes of with silicone oil of patients with general diseases gained worse BCVA than other eyes.

\section{DISCUSSION}

In the present study we have analysed retrospectively the results of primary PPV in the treatment 


\begin{tabular}{|c|c|c|c|c|c|c|c|c|}
\hline \multirow[t]{2}{*}{ BCVA (logMAR) } & \multicolumn{3}{|c|}{ Silicone oil } & \multicolumn{3}{|c|}{ SF6 gas } & \multicolumn{2}{|c|}{ Mann-Whitney tes } \\
\hline & Mean & Median & SD & Mean & Median & SD & $\mathbf{z}$ & p \\
\hline Preoperatively & 1.81 & 2.10 & 0.65 & 1.23 & 1.00 & 0.77 & 2.93 & 0.003 \\
\hline Postoperatively & 1.04 & 1.00 & 0.59 & 0.74 & 0.40 & 0.70 & 2.43 & 0.02 \\
\hline
\end{tabular}

of pseudophakic retinal detachment in a group of 63 consecutive patients.

It is known that both aphakia and pseudophakia predispose to posterior vitreous detachment (PVD) by creating changes in the ocular environment that predispose to development of retinal breaks and RD $[11,12]$. In a study by Ripandelli 453 eyes after uncomplicated phacoemulsification surgery were analysed during five years postoperatively; PVD occurred in $75 \%$ of eyes with no PVD and no lattice degeneration preoperatively, and in $87 \%$ of eyes with lattice degeneration and no PVD preoperatively [13]. Eyes with preoperative lattice degeneration and postoperative PVD showed a higher incidence of $\mathrm{RD}$ after cataract surgery $(21 \%)$ than eyes without preoperative PVD or lattice degeneration $(0.70 \%)$.

The risk factors discussed included pre-operative risk factors such as age, gender, general diseases (diabetes, hypertension), and ocular conditions as myopia, glaucoma, and IFIS, as well as surgical risk factors such as vitreous loss, posterior capsular integrity, and Nd:YAG capsulotomy. Loss of the vitreous during cataract surgery is considered to be a factor increasing the risk of $\mathrm{RD}$ to $4.9 \%$ [14]. Also posterior capsule rupture, anterior vitrectomy, high myopia, younger age, and male sex have been found - in large studies - to be predisposing factors for RD after cataract surgery [15-17]. YAG capsulotomy is considered as an important risk factor for $\mathrm{RD}$ in some studies $[18,19]$, but other studies failed to confirm this finding [20]. It has been shown in many studies that postoperative $\mathrm{RD}$ occurs more often in men than in women $[6,21]$, possibly due to higher risk of trauma in men. However, epidemiological studies have shown that a higher number of cataract surgeries are performed in female subjects and PVD is more often seen in female subjects [22].

In our study most of the patients were men, YAG capsulotomy was very rare, and myopia, intraoperative complications, and younger age were not significant variables. The significant difference in visual outcomes was found between eyes with SF6 gas tamponade and those with silicone oil tamponade.
PPV alone or in combination with scleral buckling has been performed so far for the treatment of pseudophakic RD [8-10, 23]. Different tamponade agents have been used in many case series: SF6 gas, C3F8 gas, and silicone oil [8]. Also, smaller incision surgery (25G) is used to manage pseudophakic RD [24], but it seems that 20,23, and 25G instruments are equally effective in the treatment of pseudophakic RD surgery.

The reattachment rate of $92 \%$ obtained in our group of patients is very similar to other studies $[8,23]$. Also, preoperative (1.7 log MAR) and final (0.7 log MAR) visual acuities are similar to those obtained by Won Jin [25] and other authors.

There are some limitations in visualisation of periphery while performing PPV in pseudophakic patients. The view may be limited by anterior and posterior capsular fibrosis and the aberrations (glare and reflexes) at the edge of the intraocular lens [26], or lenticular remnants and poor pupillary dilatation [5]. These difficulties cause problems especially during fluid-air exchange. From the other side internal approach in PPV makes it possible to detect and localise all the retinal breaks even if they are small and anteriorly placed, especially during scleral indentation and using the lightpipe [27]. Additionally, using perfluorocarbon liquids offers the advantage of identifying breaks by searching for the subretinal fluid outflow [28].

Primary PPV seems to be a safe procedure in the treatment of pseudophakic retinal detachment, as no intraoperative complications were reported. Most of the eyes in our study were filled with silicone oil as endotamponade; the reason for that was extensive RD and PVR. Eyes with silicone oil had preoperatively and postoperatively worse visual acuities. Postoperatively, only secondary glaucoma was observed, but it was successfully treated with topical antiglaucomatous agents.

\section{CONCLUSIONS}

In summary, PPV is an effective method of surgical treatment of $\mathrm{RD}$ following cataract surgery. 
Neither clinical nor surgical factors have been identified as responsible for visual outcomes. Patients should be informed preoperatively about the potential risk of RD after cataract surgery. Postoperative careful examination of the retina and awareness of symptoms of RD should increase the detection rate of pseudophakic RD.

\section{REFERENCES}

1. Zhu M, Huang J, Zhu B et al. Changes of Vision-Related Quality of Life in Retinal Detachment Patients after Cataract Surgery. PLoS One 2015; 10: e0120505.

2. Ramos M, Kruger EF, Lashkari K. Biostatistical analysis of pseudophakic and aphakic retinal detachments. Semin Ophthalmol 2002; 17: 206-213.

3. Mitry D, Charteris DG, Fleck BW, Campbell H, Singh J. The epidemiology of rhegmatogenous retinal detachment: geographical variation and clinical associations. Br J Ophthalmol 2010; 94: 678-684.

4. Bjerrum SS, Mikkelsen KL, La Cour M. Risk of pseudophakic retinal detachment in 202,226 patients using the fellow nonoperated eye as reference. Ophthalmology 2013; 120: 2573-2579.

5. Yoshida A, Ogasawara H, Jalkh AE, Sanders RJ, McMeel JW, Schepens CL. Retinal detachment after cataract surgery. Surgical results. Ophthalmology 1992; 99: 460-465.

6. Mahroo OA, Dybowski R, Wong R, Williamson TH. Characteristics of rhegmatogenous retinal detachment in pseudophakic and phakic eyes. Eye (Lond) 2012; 26: 1114-1121.

7. Heimann H, Bartz-Schmidt KU, Bornfeld N, Weiss C, Hilgers RD, Foerster $\mathrm{MH}$. Scleral buckling versus primary vitrectomy in Rhegmatogenous Retinal Detachment Study Group. Scleral buckling versus primary vitrectomy in rhegmatogenous retinal detachment: a prospective randomized multicenter clinical study. Ophthalmology 2007; 114: 2142-2154.

8. Arya AV, Emerson JW, Engelbert M, Hagedorn CL, Adelman RA. Surgical management of pseudophakic retinal detachments: a meta-analysis. Ophthalmology 2006; 113: 1724-1733.

9. Brazitikos PD, Androudi S, Christen WG, Stango NT. Primary pars plana vitrectomy versus scleral buckle surgery for the treatment of pseudophakic retinal detachment: a randomized clinical trial. Retina 2005; 25: 957-964.

10. Ahmadieh H, Moradian S, Faghihi H et al. Pseudophakic and Aphakic Retinal Detachment (PARD) Study Group. Anatomic and visual outcomes of scleral buckling versus primary vitrectomy in pseudophakic and aphakic retinal detachment: six-month follow-up results of a single operation - report no. 1. Ophthalmology 2005; 112: 1421-1429.

11. Mirshahi A, Hoehn F, Loren K., Hattenbach LO. Incidence of posterior vitreous detachment after cataract surgery. J Cataract Refract Surg 2009; 35: 987-991.
12. Hikichi T. Time course of development of posterior vitreous detachments after phacoemulsification surgery. Ophthalmology 2012; 119: 2102-2107.

13. Ripandelli G, Coppé AM, Parisi V et al. Posterior vitreous detachment and retinal detachment after cataract surgery. Ophthalmology 2007; 114: 692-697.

14. Bradford JD, Wilkinson CP, Fransen SR. Pseudophakic retinal detachments. The relationships between retinal tears and the time following cataract surgery at which they occur. Retina 1989; 9: 181-186.

15. Haug SJ, Bhisitkul RB. Risk factors for retinal detachment following cataract surgery. Curr Opin Ophthalmol 2012; 23: 7-11.

16. Quek DT, Lee SY, Htoon HM, Ang CL. Pseudophakic rhegmatogenous retinal detachment in a large Asian tertiary eye centre: a cohort study. Clin Experiment Ophthalmol 2012; 40: e1-e7.

17. Clark A, Morlet N, Ng JQ, Preen DB, Semmens JB. Risk for retinal detachment after phacoemulsification: a whole-population study of cataract surgery outcomes. Arch Ophthalmol 2012; 130: 882-888.

18. Ranta P, Kivelä T. Retinal detachment in pseudophakic eyes with and without Nd:YAG laser posterior capsulotomy. Ophthalmology 1998; 105: 2127-2133.

19. Koch DD, Liu F, Gill EP, Parke DW. Axial myopia increases the risk of retinal complications after neodymium-YAG laser posterior capsulotomy. Arch Ophthalmol 1989; 107: 986-990.

20. Tuft SJ, Minassian D, Sullivan P. Risk factors for retinal detachment after cataract surgery: a case-control study. Ophthalmology 2006; 113: 650-656.

21. Sheu SJ, Ger LP, Chen JF. Male sex as a risk factor for pseudophakic retinal detachment after cataract extraction in Taiwanese adults. Ophthalmology 2007; 114: 1898-1903.

22. Tanner V, Harle D, Tan J, Foote B, Williamson TH, Chignell AH. Acute posterior vitreous detachment: the predictive value of vitreous pigment and symptomatology. Br J Ophthalmol 2000; 84: 1264-1268.

23. Mendrinos E, Dang-Burgener NP, Stangos AN, Sommerhalder J, Pournaras CJ. Primary vitrectomy without scleral buckling for pseudophakic rhegmatogenous retinal detachmen. Am J Ophthalmol 2008; 145: 1063-1070.

24. Lewis SA, Miller DM, Riemann CD, Foster RE, Petersen MR. Comparison of 20-, 23-, and 25-gauge pars plana vitrectomy in pseudophakic rhegmatogenous retinal detachment repair. Ophthalmic Surg Lasers Imaging 2011; 42: 107-113.

25. Lim JW, Ryu SJ. Surgical outcomes for primary rhegmatogenous retinal detachments in patients with pseudophakia after phacoemulsification. Korean J Ophthalmol 2001; 25:-400.

26. Bartz-Schmidt KU, Kirchhof B, Heimann K. Primary vitrectomy for pseudophakic retinal detachment. Br J Ophthalmol 1996; 80: 346-349.

27. Rosen PH, Wong HC, McLeod D. Indentation microsurgery: internal searching for retinal breaks. Eye (Lond) 1989; 3: 277-281.

28. Friberg TR, Tano Y, Machemer R. Streaks (schlieren) as a sign of rhegmatogenous detachment in vitreous surgery. Am J Ophthalmol 1979; 88: 943-944. 